\title{
HOW MUCH WE ARE CONNECTED? ON DAVID KNOKE'S ECONOMIC NETWORKS (POLITY PRESS, 2012)
}

ANNA VANCSÓ ${ }^{1}$

In each and every scientific field, when a new approach rears its head, the related experts try to find its place in their own scientific system. However, with network science one question emerges again and again: Is network science a simple approach, or can we talk about a new paradigm shift? Reading David Knoke's book about economic networks - an excellent summary of preexisting research about economics from a network science approach - makes the reader feel that they "are networked in every sense"; not only concerning the economy, but - literally speaking - in every sphere and dimension of life. However, this statement today seems universal and accepted; the nature of the 'new paradigm' is the subject of on-going debate. This book does not answer this question - nor was this its purpose -; however, I think it definitely does reject the claim that "Network theory has been imported into economics as a tool...",

David Knoke is a sociologist at the University of Minnesota. He is an expert on political and organizational networks (with many articles, edited books, etc. to his credit), thus he brings his many years of experience analyzing networks to the field of economic sociology when he unpacks network mechanisms. The book is well-structured and introduces the roots of economic sociology in mainstream and alternative economic theories, as well as describing economic sociology as a separate field, and the social network perspective. In the majority of the book he describes research findings using network theory through hundreds of various examples in the field of economy, from

1 Anna Vancsó is a Ph.D. student at Corvinus University of Budapest; e-mail: vancsoanna@, gmail.com

2 Arrow, Kenneth J. 2009. "Some Development in Economic Theory Since 1940: An Eyewitness Account” Annual Review of Economics 1:1-16 
the micro-level (rational choices, personal networks) to macro-level analysis (global economic networks). As the book itself is an integrated summary of the findings of economic network research, this review is thus a 'summary of a summary' in which I intend to follow the structure of the book.

\section{THE ROOTS OF ECONOMIC SOCIOLOGY}

As an introduction Knoke begins by describing classical theories that concern rational actors, utility maximization, methodological individualism or perfect possession of information, etc. He also describes alternative theories such as the theory of labor, old institutional economics and evolutionary and behavioral economics. The Introduction also serves as proof of the incompleteness of these theories for use in describing the 21th century economy. Knoke then provides a short description of economic sociology as such, using sociological ideas and approaches for analyzing economic processes. He agrees with other researchers that one of the main contributions of the sociological perspective in economic theory is the concept of embeddedness ${ }^{3}$; that actors and firms are both embedded in a complex social, political, cultural and economic context which shapes their beliefs and decisions. This idea advocated the birth of theories that include (but are not limited to) neoinstitutional theories that examine systems of rules and regulations and their influence on social actions; cultural theories that concentrate on the subjective meanings actors attribute to social objects and actions; and social network theories - elaborated in the book under review - where social actors are highly interdependent decision makers whose behaviors mutually influence each other through their varied network connections. The main goal of employing the social network perspective is to identify specific mechanisms that connect individuals (the micro-level) and institutions (the macro-level), but it is also good for examining the relations between micro and macro levels and their effects. The first chapter of the book thus serves as a short introduction to the development of economic theories, concepts, definitions, etc. and serves as a basic platform - although the following sections can also be built on and understood by readers without deep knowledge of the former.

3 Following Karl Polányi's concept that unfolds in his book The Great Transformation. 


\section{ECONOMIC NETWORKS FROM MICRO TO MACRO LEVEL}

The remaining part of the book consists of an excellent, integrated description of findings about economic networks at different social levels with a focus on organizations. The author also provides a short summary of Networks in Markets, the central institutions of the capitalist economy (labor, consumer and producer markets), as a 'warm-up section'. This section also introduces the main terms used in network science. Concerning labor markets the wellknown strong and weak ties theory of Granovetter (1973) is introduced; however, Knoke stresses that 'both' ties are of differing utility depending on cultural embeddedness. This is also highlighted in a discussion of the role of the "demonstration effect" or "snob effect" in the consumer market. DiMaggio and his colleagues (1998) examined 'control-of-embeddedness' in consumer and producer markets and describe the positive and negative effects of social embeddedness on economic activity. Through these examples the importance of connections between actors in seeking information, advice or help - intentionally or unintentionally - becomes quite visible.

Knoke then turns our attention to the world of organizations, moving from micro to macro analysis; the reader will get an overview of intra-organizational networks (defined as networks of actors embedded in both egocentric and complete network structures), where actors and networks shape one another. The first research on egocentric networks was conducted in the middle of the $20^{\text {th }}$ century. However, using the method for developing an organization's structure and increasing its capacity is quite a new application. Researchers of the intra-organizational/small network approach - such as Johnson-Cramer (2007) or Trond Petersend (2000) and their colleagues - concentrate on the structure of micro-networks (described mainly by using centrality scores) and the characteristics of the different positions of actors. (tertius, broker, clique, etc.) The impact of social capital, formal and informal connections, trust or basic demographic features such as race, gender or ethnicity on performance, learning processes or even stress are at the center of research related to inner networks. This is because, with a well-designed formal network, these effects can be strengthened or weakened. In this chapter Knoke devotes special attention to team work, as he considers that this form of cooperation is of particular importance in today's organizations. The research by Biran Uzzi and Jarret Spiro (2005) or Ray Reagans and Ezra Zuckerman (2001) that is presented focuses on the significance of diversity in these networks. The results prove the importance of network structure as network diversity appears to be more significant than demographic diversity. Intra-organizational 
research (that today is not the focus of scientists but rather experts in the field of organizational development) still plays a crucial role due to the importance awarded to good performance that is affected by formal and informal networks (as inter-organizational and global connections are based on these factors).

Knoke presents four types of inter-organizational networks in his reflections about the most recent phenomena in business life. These four are start-up networks, business groups, interlocking boards of directors and strategic alliances. The evolution of start-ups - based on theories of entrepreneurs by Schumpeter (1932) or Kirzner (1973) - is a core research area today as the majority of these organizations are founded through informal networks (family, friends), but they are also quite strongly determined by macro-level influences such as actual public policies, market development or technical innovations. The level of homogeneity and heterogeneity is crucial for startups as they are mainly created among friends in a homogenous environment, and having strong ties in an egocentric business network can lead to negative impacts when seeking cooperation and funding from outside. In contrast, being able to build connections with diverse economic actors outside of the egocentric network can bring success. In connection with business groups, Knoke offers the example of the family-centered business conglomerates of the Far-East, formerly examined by (e.g.) Michael Gerlach and James Lincoln (2004) which have recently declined in prominence due to the strengthening of industry-based relations, but that still have an influence on today's business relations through their crucial connections. Recent research has concentrated on examining direct state intervention in economic affairs (mainly in China as well as the post-soviet countries after the fall of the USSR); findings indicate that the transformation from state socialist to market economy (private ownership) in the post-soviet countries happened because of the existence of inter-organizational networks inherited from the socialist system, not despite them. Interlocking directorates are also the center of attention both in economic and elite research, with the network perception appearing as a new approach in this field. These organizations are created for the purpose of acquiring new knowledge, skills, and technologies. Interestingly, they have often had negative impacts on companies because they have diverted attention away from structuring intra-organizational networks, as well as allowing the private interests of CEOs to dominate shareholder interests. Strategic alliances are Knoke's last examples of inter-organizational networks. These have primarily been examined on a micro-level, but recent research by (e.g.) Pinar Ozcan and Kathleen Eisenhardt (2009) was conducted on the evolution of large alliance systems. Strategic alliances are co-operative agreements among independent organizations related to the accomplishment of a specific 
project/task, where the companies involved share the benefits and managerial control of the given project. In forming alliances, the market position of a given company in the economic network plays a significant role; poorlypositioned companies have less chance of creating symmetric alliances; well-positioned ones, however, tend to form strategic alliances according to the homophile principle (companies with similar network features) or functional interdependence (specialized firms can require additional competencies - complementary organizational capabilities). Results indicate that the greatest probability of strategic alliances occurring is when both are available. Evidently, companies tend to form alliances with companies they have gained trust and experience with, thus the social capital of the CEO is quite an important factor in initiating alliances, but the resulting performance of the alliance is also a crucial element in whether co-operation continues. At a macro-level the network structure of strategic alliances seems to be a scale-free ${ }^{4}$ network; however the largest components of it resemble a coreperiphery structure.

As multinational connections are increasingly significant in economic life, the last chapter of the book focuses on global networks by analyzing supply and commodity chains, world-city networks, the network of the global financial crisis in 2008 and the theory of a recently formed transnational capitalist class. Not surprisingly, research about the first two (borrowing from research by Gary Gereffi [1994] and Kenney and Florida [1994] on supply and commodity chains, and the research of John Friedmann [1986] into global city networks) agrees that a network structure exists as world cities integrate regional, national and international economies. Recent research by Arthur Alderson and Jason Beckfield (2004) examined the networks of headquarters and branch locations of Fortune Global 500 corporations. Findings indicated (based on pre-listed network centrality scores) that a small number of cities are monopolizing power and prestige; ${ }^{5}$ thus the center-periphery structure in both cases appears quite visible. In accordance with the global financial crisis, experts identified the main antecedents of the process (just to mention some of them here; the existence of a shadow banking system and the shift in public policy away from business regulation to free markets, etc.) but network scientists have also described how small disturbances can result in a global

4 Scale free: Skewed distributions of ties among organizations is consistent with the power of law. in Barabási, Albert László and Réka Albert. 1999."Emergence of Scaling in Random Networks."Science 286:509-512

5 Based on a block-model they identified groups of cities: the 4 most powerful cities formed one single block with a high number of outside relations. 
crises. Based on an interdependent banking system, financial organizations generally lend and borrow deposits from each other; the clustered and asymmetrical form of lending increases the fragility of the network and tests reveal that such fragile (or incomplete) networks have a higher risk of propagating crises. Allen and Douglas Gale (2000) created a contagion model which shows that the credit crisis diffused through the financial network in an analogous way to disease-related contagion processes, and that due to this effect the crisis was able to spread faster than would have been the case with complete networks. Thus the network structure in this case had a crucial impact. In this last section Knoke briefly describes research findings about so-called Transnational Capitalist Class theory, based on Karl Marx's critical tradition. According to research by Leslie Sklair (1997) and William Robinson and Jerry Harris (2000), the members of this class are professionals, politicians, TNC executives and consumer elites that have shared features; they are more international than national-oriented, cosmopolites who share similar lifestyles and occupy interlocking positions. How is it possible to identify the networks of such people? By mapping their social connections through their co-presence in economic organizations (firm by person and person by firm matrixes); see research conducted by (e.g.) William Carroll and Meindert Fennema (2002). Results, however, are quite controversial: the number of multinational boards has increased dramatically; however, national connections still seem to be of crucial importance. There are also some other institutional forms that have increased international cooperation (namely, the growing number of so-called 'think tanks' that have been criticized for representing international interests in order to support transnational elites). Based on these findings, the existence of a transnational elite class seems verifiable, but - as Knoke also states - more elaborate investigation must be conducted if we are to understand the whole process.

Knoke closes up the book by stressing the importance of constructing network theory based on network principles, instead of taking over the theories of other disciplines. According to the author, the first steps have already been taken by Steven Borgatti and his colleagues (2011), who constructed a flow and bond model as a foundational element for network analysis. The combination of these models is a good source of new, complex network theories that can better explain economic actions. Another ambition of network analysts is to create a multi-level theory of economic networks, thereby connecting macro-level structures with micro-level action, basically following Coleman's (1986) macro-micro-macro schema. In conclusion, the writer highlights the importance of the network approach in analyzing the recent effects of politics on economics. He states that present times are "Truly 
troubling times for the world, but also [represent] exciting opportunities [...] for economic network analysts."(Knoke, 2012:196)

David Knoke undertook the task of integrating and summarizing the most important approaches of economic sociology from a network perspective into a digestible form. His book is perfect reading for anyone who is interested in economic networks. It is also really useful for anyone who works in the field of social sciences who would like to get an overview of this new perspective. 